\title{
Neuropsychiatric Correlates of Small Vessel Disease Progression in Incident Cognitive Decline: Independent and Interactive Effects
}

\author{
Cheuk Ni Kan ${ }^{\text {a,b,1 }}$, Bibek Gyanwali ${ }^{\text {a,b,1 }}$, Saima Hilal ${ }^{\text {a,b,c,d }}$, Kok Pin Ng ${ }^{\mathrm{e}}$, \\ Narayanaswamy Venketasubramanian ${ }^{\mathrm{f}}$, Christopher Li-Hsian Chen ${ }^{\mathrm{a}, \mathrm{b}}$ and $\mathrm{Xin} \mathrm{Xu}^{\mathrm{b}, \mathrm{g}, *}$ \\ ${ }^{a}$ Memory Aging and Cognition Centre, National University Health System, Singapore, Singapore \\ ${ }^{\mathrm{b}}$ Department of Pharmacology, National University of Singapore, Singapore, Singapore \\ ${ }^{\mathrm{c}}$ Departments of Epidemiology and Radiology and Nuclear Medicine, Erasmus University Medical Center, \\ Rotterdam, the Netherlands \\ ${ }^{\mathrm{d}}$ Saw Swee Hock School of Public Health, National University of Singapore, Singapore, Singapore \\ ${ }^{\mathrm{e}}$ Department of Neurology, National Neuroscience Institute, Singapore, Singapore \\ ${ }^{\mathrm{f}}$ Raffles Neuroscience Centre, Raffles Hospital, Singapore, Singapore \\ ${ }^{\mathrm{g}}$ Zhejiang University School of Medicine, Hangzhou, Zhejiang, China
}

Accepted 18 November 2019

\begin{abstract}
.
Background: Cerebral small vessel disease (SVD) and neuropsychiatric symptoms (NPS) independently increase the risk of cognitive decline. While their co-existence has been reported in the preclinical stage of dementia, longitudinal data establishing the prognosis of their associations, especially in an Asian context remains limited.

Objective: This study investigated the role of SVD and NPS progressions on cognitive outcomes over 2 years in a dementiafree elderly cohort.

Methods: 170 dementia-free elderly with baseline and 2-year neuropsychological assessments and MRI scans were included in this study. White matter hyperintensities (WMH), lacunes, and microbleeds (CMBs) were graded as markers of SVD. The Neuropsychiatric Inventory (NPI) was used to measure NPS. Generalized estimating equations modelling evaluated the relationship between NPI change and SVD progression. Logistic regression evaluated the risk of incident cognitive decline with both SVD and NPS. All models were adjusted for demographics, baseline cerebrovascular diease, and medial temporal lobe atrophy.

Results: Higher NPI scores were associated with higher SVD burden at baseline. Subjects with WMH progression had greater increase in total NPI $(\beta[\mathrm{SE}]=0.46[0.19], p=0.016)$, driven by hyperactivity subsyndrome $(\beta[\mathrm{SE}]=0.88[0.34]$, $p=0.007)$. Subjects with incident CMBs had greater increase in psychosis subsyndrome $(\beta[S E]=0.89[0.30], p<0.001)$. Subjects with progressions in both SVD and NPS were more likely to develop cognitive decline over 2 years (OR[95\% $\mathrm{CI}]=4.17[1.06-16.40], p<0.05)$.

Conclusion: Our findings support worsening of NPS as a clinical indicator of SVD progression and are associated with cognitive decline over 2 years. Early detection of NPS and targeted interventions on SVD burden may improve NPS outcomes.
\end{abstract}

Keywords: Cerebral small vessel disease, cognitive impairment, dementia, lacune, microbleeds, neurobehavioral symptoms, Neuropsychiatric Inventory, white matter hyperintensities

\footnotetext{
${ }^{1}$ These authors contributed equally to this work.
} 


\section{INTRODUCTION}

Cerebral small vessel disease (SVD), including white matter hyperintensities (WMH), lacunar infarcts, and cerebral microbleeds (CMBs), are indicators of brain structural abnormalities involving the small arteries, arterioles, venules, and capillaries of the brain [1]. These lesions may represent various ischemic, hemorrhagic, and inflammatory damages and are frequently observed among older adults in brain magnetic resonance imaging (MRI) [2]. SVD is an established contributor to cognitive impairment and dementia, especially in Asian populations $[3,4]$.

Neuropsychiatric symptoms (NPS) of depression, apathy, disinhibition, and psychosis are related to cognitive impairment, poorer quality of life, increased caregiver burden, and early institutionalization [5-8]. Even in the absence of concurrent cognitive impairment, NPS are associated with worse prognosis and a higher risk of developing dementia $[9,10]$. Previous studies have shown cross-sectional associations between SVD burden and delusions in Alzheimer's disease (AD) patients [11], between lacunes and depressive symptoms in elderly patients with silent strokes [12], and between microbleeds and disinhibition among community-dwelling older adults [13].

However, no longitudinal studies have investigated a wide range of NPS in relation to all three SVD markers of WMH, lacune, and CMBs. It is also unclear if the specific patterns of association between SVD markers and NPS are independent of other brain structural abnormalities, such as large vessel disease and atrophy. Given the adverse outcomes of NPS, a better understanding of the longitudinal relationships between NPS, SVD, and cognitive function would help identify at-risk individuals and enhance strategies in disease prevention. In the present study, we aim to examine, in a sample of dementia-free Asian elderly from the memory clinic, 1) the association between SVD and NPS at baseline; 2) the association between SVD progression and longitudinal changes in NPS; and 3) the interactive effect of SVD and NPS on cognitive decline. We hypothesized that: 1) SVD markers of WMH, CMBs, and lacune are associated with NPS subsyndromes at baseline; 2) SVD progressions are associated with greater increase in the severity of NPS at follow-up; and 3) progressions of SVD and NPS are associated with worse prognosis at follow-up.

\section{METHODS}

\section{Study sample}

This study consisted of participants from an ongoing prospective case-control study who were recruited from the memory clinic at the National University Hospital in Singapore. Subjects were considered eligible if they were aged 50 and above, had sufficient language skills for neuropsychological assessment, fulfilled diagnostic criteria [14], and provided informed consent. Exclusion criteria included diagnosis of dementia, major psychiatric illness or substance abuse disorder, cognitive impairment caused by a history of traumatic brain injury, multiple sclerosis, tumor, epilepsy or systemic disease, and significant visual and auditory impairments. Between August 2010 and December 2015, all subjects underwent comprehensive evaluation including clinical examination, neuropsychological and neuropsychiatric assessments, and $3 \mathrm{~T}$ brain MRI at baseline and were followed up for two years (Fig. 1). Ethics approval was obtained from the National Healthcare Group Domain-Specific Review Board. This study was conducted in accordance with the Declaration of Helsinki. Written informed consent was obtained in the preferred language of the participants.

\section{Clinical diagnosis}

Patient diagnoses were made at weekly consensus meetings, held among clinicians, psychologists, and research personnel. Details of the assessments and MRI scans were reviewed. Domain impairment on a locally validated standardized neuropsycholog-

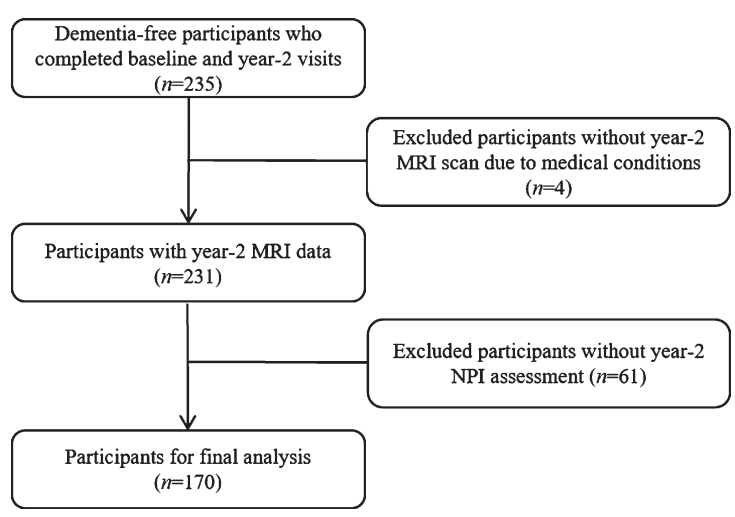

Fig. 1. Flowchart of study participants. 
ical battery (the vascular dementia battery, VDB) [15] was defined as $\geq 1.5$ standard deviations below education-adjusted norms. Subjects who had no objective cognitive impairment on the VDB or functional impairment, yet with or without subjective cognitive impairment, were diagnosed as no cognitive impairment (NCI). In the present study, 11 (17.2\%) NCI participants had subjective cognitive impairment. Subjects with subjective complaints and objective impairment on at least one cognitive domain on the VDB but functionally independent, hence not meeting DSM-IV for dementia, were diagnosed as mild cognitive impairment (MCI) [16]. Dementia cases were diagnosed according to DSM-IV criteria and were excluded from this study.

\section{Assessment of neuropsychiatric symptoms}

Suitable informants with frequent interactions with the study subjects for at least 10 hours a week were administered the 12-item Neuropsychiatric Inventory (NPI) [17] at both visits. The NPI is a structured interview which investigates the presence, frequency, severity, and caregiver distress of 12 behavioral and psychological symptoms. For each symptom, the informant was asked whether the behavior had been present in the past month and if it was a change from the subject's usual behavior. A total score for each symptom was derived by multiplying the frequency and severity of the symptom and the total NPI score was the sum of all individual symptom scores. Subsequently, individual symptoms were classified into four subsyndromes as suggested by the European Alzheimer's Disease Consortium [18, 19]:

1. Hyperactivity (agitation, elation, disinhibition, irritability, and aberrant motor behaviors);

2. Psychosis (delusions, hallucinations, and nighttime behaviors);

3. Affective symptoms (depression and anxiety);

4. Apathy (apathy and appetite/eating behaviors).

The score for each subsyndrome was the sum of all symptom scores in the subsyndrome.

\section{Neuroimaging}

MRI scans were performed on a 3-T Siemens Magnetom Trio Tim Scanner, with a 32 -channel head coil at the Clinical Imaging Research Center of the National University of Singapore. The standardized neuroimaging protocol included three-dimensional
(3D) T1-weighted, T2-weighted, fluid-attenuated inversion recovery (FLAIR), susceptibility weighted images (SWI) sequence and a 3D time of flight magnetic resonance angiography (TOFMRA). Identical MRI protocol and scanner were used for baseline and year-2 visits. MRI markers of cerebrovascular disease were graded based on the Standards for Reporting Vascular changes on Neuroimaging (STRIVE) criteria [20]:

- Lacunes were defined as round or ovoid lesions involving the subcortical regions, 3 to $15 \mathrm{~mm}$ in diameter, with a low signal on T1-weighted images and FLAIR, a high signal on T2-weighted images and a hyperintense rim with a centre following the cerebrospinal fluid intensity [20]. Total number of lacunes were counted and $\geq 1$ lacune was labelled as the presence of any lacune. Lacunes were differentiated from enlarged perivascular spaces, which are lesions that are well defined, round, ovular or tubular in shape with a smooth margin, less than $5 \mathrm{~mm}$ in size, and in the absence of a hyperintense rim [21].

- CMBs were defined as focal, round hypointense lesions with blooming effect on SWI and graded using the Microbleed Anatomical Rating Scale (MARS) [22]. As a threshold effect of multiple CMBs ( $\geq 2$ CMBs) was previously reported on clinically relevant symptoms [13,23, 24], the total number of CMBs were counted and $\geq 2$ CMBs was labelled as the presence of multiple CMBs.

- WMH was defined as hyperintense on T2 and FLAIR sequences and hypointense on T1weighted images. WMH was graded using the Modified Fazekas Scale (absent $=0$, punctate $=1$, early confluent $=2$, and confluent $=3$ ) [25] and a score of $\geq 2$ was labelled as having moderatesevere WMH [26].

Progressions of SVD were assessed by comparing baseline and year-2 scans. Progression of WMH was graded using the Modified Rotterdam Progression Scale [27] and labelled as presence or absence of WMH progression. The presence of multiple new CMBs ( $>1)$ seen on year- 2 scans which were absent on baseline scans was labelled as having incident multiple CMBs [28]. The presence of any new lacune seen on year- 2 scans which were absent on baseline scans was labelled as having incident lacune [28]. Subjects with regression of CMBs $(n=7)$ were included in the group without incident CMBs. No subjects had a regression for WMH or lacunes. 
In addition, cortical infarcts [20] and intracranial stenosis [29] were graded as markers of large vessel disease. The severity of medial temporal lobe atrophy (MTA) was also assessed and was graded on coronal sections using the Scheltens' Scale $(0=$ normal, $1=$ mild, $2=$ mild-moderate, $3=$ moderate, $4=$ severe) $[30,31]$ and a MTA score of $\geq 2$ was labelled as having significant MTA. All MRI scans were graded by one rater (B.G.) who was blinded to the clinical history of the subjects and confirmed by an experienced fellow (S.H.). Good-toexcellent intra-rater agreement of all MRI markers was showed by the intra-class correlation coefficients, which are detailed elsewhere [28].

\section{Demographics and vascular risk profile}

All subjects were administered a detailed questionnaire to collect information on age, gender, years of formal education, and ethnicity. Vascular risk profile was obtained for all subjects through clinical interview, physical examination, and review of laboratory and medical records. This included hypertension, defined as systolic blood pressure $\geq 140 \mathrm{mmHg}$ and/or diastolic blood pressure $\geq 90 \mathrm{mmHg}$ or the use of antihypertensive medication; hyperlipidemia, defined as total cholesterol level $\geq 4.14 \mathrm{mmol} / 1$ or the use of lipid-lowering medication; diabetes mellitus, defined as glycated hemoglobin $\geq 6.5 \%$ or the use of antidiabetic medication; heart disease, defined as a previous diagnosis of myocardial infarction, congestive heart failure, atrial fibrillation, or intervention procedures such as angioplasty, or stenting; and history of smoking (ever/never).

\section{Outcome measures}

All subjects underwent a standardized clinical examination and neuropsychological assessments at baseline and year-2 follow-up and were classified if they had any baseline and progression of SVD and/or NPS. Incident cognitive decline was defined as conversion from $\mathrm{NCI}$ to $\mathrm{MCI}$, or from $\mathrm{MCI}$ to dementia, from baseline to year-2.

\section{Statistical analysis}

Cross-sectional associations of SVD markers (moderate-severe WMH, multiple CMBs, and lacune) with NPI scores at baseline were assessed using generalized linear modelling, adjusting for demographics, Clinical Dementia Rating (CDR) score, vascular risk factors, significant MTA $(n=20)$, and the presence of large vessel disease markers. Longitudinal analyses of NPI scores with progression of SVD markers were examined using generalized estimating equations (GEE) modelling. The differential rates of change in NPI scores as a function of baseline and progression of SVD were examined by applying a marker $x$ time interaction effect in the GEE models, adjusting for demographics, time, baseline CDR score, small and large vessel disease markers, total NPI score, and significant MTA. The effects of incident lacune were not examined due to the low occurrence in this sample $(n=5)$. Subsequently, the likelihood of incident cognitive decline at year-2 was examined using logistic regression analysis with 95\% confidence interval (CI), adjusting for demographics, baseline CDR, total NPI score, large vessel disease markers, and significant MTA. All analyses were performed using SPSS version 25 software, and statistical significance was determined as two-tailed $p$ value $<0.05$. Bonferroni correction was performed to obtain adjusted significance level for individual NPS subsyndrome: $\mathrm{p} \approx 0.05 / 4 \approx 0.0125$.

\section{RESULTS}

\section{Baseline characteristics}

A total of 235 dementia-free subjects who completed baseline and year-2 visits were recruited in this study. Four who did not perform MRI scans due to medical conditions and another 61 without NPI assessment at year-2 were excluded, leaving a total of 170 subjects (64 NCI, $106 \mathrm{MCI})$ for the final analysis. Other than being older $(73.3 \pm 7.2$ versus $69.5 \pm 7.3, p<0.01)$, excluded subjects $(n=65)$ did not differ from included subjects in demographics, diagnosis, clinical features, cognitive scores, neuropsychiatric profile, and MRI findings (all ps $>0.05$ ). Characteristics of the current sample were summarized in Table 1. Figure 2 shows the frequencies of the four NPS subsyndromes at baseline and year-2.

\section{Baseline associations of SVD with NPS}

As shown in Fig. 3, the presence of moderatesevere $\mathrm{WMH}(\beta[\mathrm{SE}]=1.12[0.27], p<0.001)$ and multiple CMBs $(\beta[\mathrm{SE}]=0.82[0.29], p=0.005)$ were associated with higher total NPI scores at baseline. Subjects with moderate-severe WMH had higher hyperactivity $(\beta[\mathrm{SE}]=1.22[0.38], p=0.001)$ 
Table 1

Characteristics of Study Sample

\begin{tabular}{|c|c|}
\hline Characteristics & $\begin{array}{c}\text { All } \\
(n=170)\end{array}$ \\
\hline \multicolumn{2}{|l|}{ Baseline Demographics \& risk factors } \\
\hline Age, $M(\mathrm{SD})$ & $69.5(7.3)$ \\
\hline Female, n (\%) & $86(50.6)$ \\
\hline \multicolumn{2}{|l|}{ Ethnicity, n (\%) } \\
\hline Chinese & $139(81.8)$ \\
\hline Indian & $14(8.2)$ \\
\hline Malay & $17(10.0)$ \\
\hline Education, $0-6$ years, $\mathrm{n}(\%)$ & $66(38.8)$ \\
\hline Hypertension, yes, $\mathrm{n}(\%)$ & $111(65.3)$ \\
\hline Diabetes, yes, n (\%) & $49(28.8)$ \\
\hline Hyperlipidemia, yes, n (\%) & $128(75.3)$ \\
\hline Smoking history, yes, n (\%) & $45(26.5)$ \\
\hline Heart disease, yes, $\mathrm{n}(\%)$ & $25(14.7)$ \\
\hline ApoE4 status, positive, $\mathrm{n}(\%)$ & $40(23.5)$ \\
\hline \multicolumn{2}{|l|}{ Baseline Cognitive profile } \\
\hline Baseline MMSE, M (SD) & $25.7(3.0)$ \\
\hline Baseline MoCA, M (SD) & $22.5(4.1)$ \\
\hline CDR global $0.5, \mathrm{n}(\%)$ & $83(48.8)$ \\
\hline \multicolumn{2}{|l|}{ Baseline Neuropsychiatric symptoms, M (SD) } \\
\hline Total score & $1.3(3.3)$ \\
\hline Hyperactivity & $0.5(1.8)$ \\
\hline Psychosis & $0.3(1.2)$ \\
\hline Affective symptoms & $0.1(0.7)$ \\
\hline Apathy & $0.3(1.4)$ \\
\hline \multicolumn{2}{|l|}{ SVD markers, n (\%) } \\
\hline \multicolumn{2}{|l|}{ Baseline } \\
\hline Presence of moderate-severe WMH & $87(51.2)$ \\
\hline Presence of multiple CMBs & $34(20.0)$ \\
\hline Presence of any lacune & $55(32.4)$ \\
\hline \multicolumn{2}{|l|}{ Progression } \\
\hline Presence of WMH progression & $95(55.9)$ \\
\hline Presence of multiple incident CMBs & $13(7.6)$ \\
\hline Presence of incident lacune & $5(2.9)$ \\
\hline \multicolumn{2}{|l|}{ Other cerebrovascular disease markers, $\mathrm{n}(\%)$} \\
\hline Presence of cortical stroke & $22(12.9)$ \\
\hline Presence of intracranial stenosis & $24(14.1)$ \\
\hline
\end{tabular}

MMSE, Mini-Mental State Examination; MoCA, Montreal Cognitive Assessment; CDR, Clinical Dementia Rating, SVD, small vessel disease; $\mathrm{WMH}$, white matter hyperintensities; CMB, cerebral microbleed.

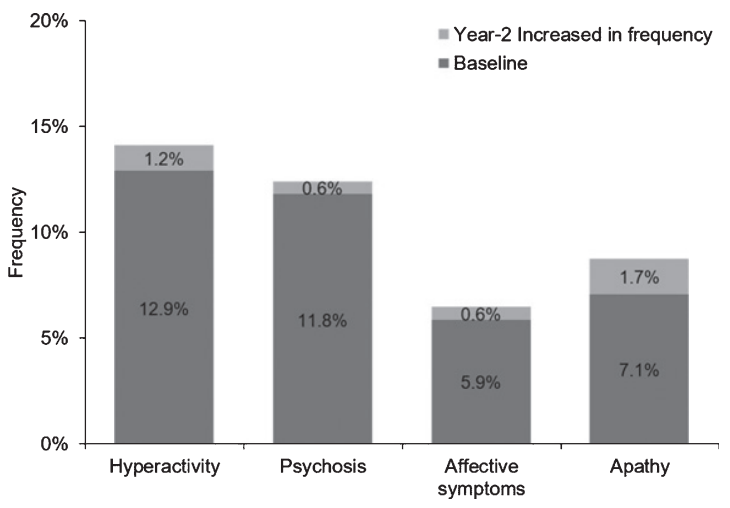

Fig. 2. Bar graph of the frequency of NPS subsyndromes at baseline and year-2.

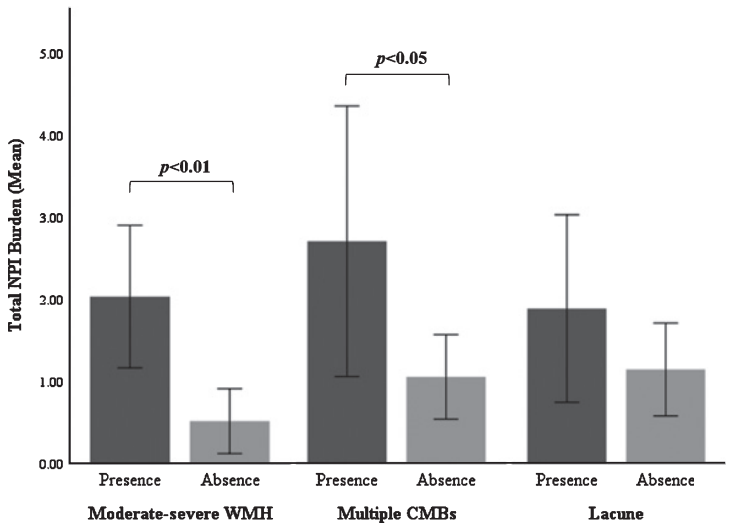

Fig. 3. Associations between SVD markers and total NPS severity at baseline.

and apathy $(\beta[\mathrm{SE}]=2.50[0.64], p<0.001)$ subsyndromes. Subjects with multiple CMBs had higher psychosis $(\beta[\mathrm{SE}]=1.57[0.49], p=0.001)$ and affective symptoms $(\beta[\mathrm{SE}]=1.79[0.62], p=0.004)$. The presence of any lacune was associated with higher apathy subsyndrome $(\beta[\mathrm{SE}]=0.94[0.45], p=0.038)$ but the association did not reach significance after Bonferroni correction $(p>0.0125)$.

\section{Longitudinal associations of SVD with changes in NPS severity}

Significant increase in total NPI score was observed among subjects between baseline and year- 2 (mean difference $=0.72,95 \% \mathrm{CI}=0.56-0.94$, $p<0.001)$. Having any lacune at baseline was associated with a higher increase in affective symptoms $(\beta$ $[\mathrm{SE}]=0.91[0.24], p<0.001)$. No other baseline SVD markers were significantly associated with changes in NPI scores (Table 2). After controlling for covariates including baseline cognitive status, NPI score, and MRI markers, subjects with WMH progression had a greater increase in total NPI score $(\beta[\mathrm{SE}]=0.46$ [0.19], $p=0.0160)$, particularly in the hyperactivity subsyndrome $(\beta[\mathrm{SE}]=0.88[0.34], p=0.0007)$ (Table 3). In addition, subjects with incident multiple CMBs had a greater increase in the psychosis subsyndrome $(\beta[\mathrm{SE}]=0.89[0.30], p<0.001)$ (Table 3).

\section{Incident cognitive decline in the presence of SVD} and/or NPS

At year-2, 11 NCI subjects (6.5\%) developed incident $\mathrm{MCI}$ and $10 \mathrm{MCI}$ subjects (5.9\%) developed 
Table 2

Associations of Baseline SVD with Changes in Neuropsychiatric Symptoms

\begin{tabular}{|c|c|c|c|c|c|}
\hline \multirow[b]{2}{*}{ Baseline SVD markers } & \multirow[b]{2}{*}{$\begin{array}{c}\text { Total NPI } \\
\beta(\mathrm{SE})\end{array}$} & \multicolumn{4}{|c|}{ Neuropsychiatric Subsyndromes } \\
\hline & & $\begin{array}{c}\text { Hyperactivity } \\
\beta \text { (SE) }\end{array}$ & $\begin{array}{c}\text { Psychosis } \\
\beta \text { (SE) }\end{array}$ & $\begin{array}{c}\text { Affective } \\
\beta \text { (SE) }\end{array}$ & $\begin{array}{l}\text { Apathy } \\
\beta \text { (SE) }\end{array}$ \\
\hline \multicolumn{6}{|l|}{ Moderate-severe WMH } \\
\hline Model 1 & $0.21(0.17)$ & $0.24(0.29)$ & $0.09(0.22)$ & $0.53(0.39)$ & $0.01(0.31)$ \\
\hline Model 2 & $0.01(0.18)$ & $-0.13(0.35)$ & $-0.19(0.43)$ & $0.50(0.34)$ & $0.03(0.32)$ \\
\hline \multicolumn{6}{|l|}{ Multiple CMBs } \\
\hline Model 1 & $0.07(0.19)$ & $-0.04(0.27)$ & $0.25(0.26)$ & $0.70(0.32)$ & $-0.05(0.29)$ \\
\hline Model 2 & $0.06(0.20)$ & $-0.07(0.28)$ & $0.24(0.26)$ & $0.68(0.33)$ & $0.05(0.31)$ \\
\hline \multicolumn{6}{|l|}{ Any lacune } \\
\hline Model 1 & $-0.32(0.18)$ & $0.05(0.22)$ & $-0.61(0.28)$ & $0.91(0.25)^{* *}$ & $-0.76(0.29)$ \\
\hline Model 2 & $-0.32(0.18)$ & $0.07(0.22)$ & $-0.54(0.25)$ & $0.91(0.24)^{* *}$ & $-0.79(0.30)$ \\
\hline
\end{tabular}

Model 1: controlled for age, gender, CDR score, time, baseline NPS score, other baseline small and large vessel disease markers (moderate-severe WMH, multiple CMBs, lacune, cortical infarct, intracranial stenosis), and significant MTA. Model 2: additionally controlled for markers of SVD progression (WMH progression, incident CMBs, incident lacune). $* * p<0.0125$.

Table 3

Associations of SVD Progression with Changes in Neuropsychiatric Symptoms

\begin{tabular}{|c|c|c|c|c|c|}
\hline \multirow[b]{2}{*}{ SVD markers } & \multirow[b]{2}{*}{$\begin{array}{c}\text { Total NPI } \\
\beta(\mathrm{SE})\end{array}$} & \multicolumn{4}{|c|}{ Neuropsychiatric Subsyndromes } \\
\hline & & $\begin{array}{c}\text { Hyperactivity } \\
\beta \text { (SE) }\end{array}$ & $\begin{array}{c}\text { Psychosis } \\
\beta(\mathrm{SE})\end{array}$ & $\begin{array}{l}\text { Affective } \\
\beta \text { (SE) }\end{array}$ & $\begin{array}{l}\text { Apathy } \\
\beta \text { (SE) }\end{array}$ \\
\hline \multicolumn{6}{|c|}{ WMH progression } \\
\hline Model 1 & $0.47(0.19)^{*}$ & $0.89(0.34)^{* *}$ & $0.43(0.23)$ & $0.05(0.33)$ & $-0.02(0.36)$ \\
\hline Model 2 & $0.46(0.19)^{*}$ & $0.88(0.34)^{* *}$ & $0.37(0.25)$ & $0.04(0.32)$ & $-0.01(0.35)$ \\
\hline \multicolumn{6}{|c|}{ Multiple incident CMBs } \\
\hline Model 1 & $0.31(0.23)$ & $0.24(0.28)$ & $0.94(0.32)^{* *}$ & $0.09(0.52)$ & $-0.32(0.42)$ \\
\hline Model 2 & $0.21(0.22)$ & $0.13(0.26)$ & $0.89(0.30)^{* *}$ & $0.16(0.54)$ & $-0.33(0.44)$ \\
\hline
\end{tabular}

Model 1: controlled for age, gender, CDR score, time, baseline NPS score, baseline small and large vessel disease markers (moderate-severe WMH, multiple CMBs, lacune, cortical infarct, intracranial stenosis), and significant MTA. Model 2: additionally controlled for other markers of SVD progression (WMH progression, incident CMBs, incident lacune). ${ }^{* *} p<0.0125,{ }^{*} p<0.05$.

Table 4

Odds Ratio (OR) of Incident Cognitive Decline

\begin{tabular}{lc}
\hline Factors & OR $(95 \%$ CI $)$ \\
\hline Baseline & \\
$\quad$ Only SVD $(n=80)$ & $2.19(0.54-8.87)$ \\
Only NPS $(n=8)$ & $2.33(0.17-32.09)$ \\
$\quad$ Both SVD and NPS $(n=32)$ & $2.04(0.26-16.17)$ \\
Progression & $0.81(0.21-3.18)$ \\
$\quad$ Only SVD progression $(n=68)$ & $2.29(0.32-16.54)$ \\
$\quad$ Only NPS progression $(n=11)$ & $4.17(1.06-16.40)^{*}$ \\
Both SVD and NPS progressions $(n=27)$ & \\
\hline Controlled for age, gender, education, baseline CDR, baseline total \\
NPS score, baseline presence of large vessel disease markers, and \\
significant MTA. ${ }^{*} p<0.05$.
\end{tabular}

dementia. Decliners were less educated $(61.9 \%$ versus $35.6 \%$ with $0-6$ years of education, $p=0.02$ ) and had more severe WMH at baseline $(71.4 \%$ versus $48.3 \%$ with moderate-severe WMH, $p=0.047)$. Neither the presence of SVD nor NPS alone predicted cognitive decline independently. However, subjects having progressions in both SVD and NPS had a 4-times higher odds of decline (Odds Ratio [95\% $\mathrm{CI}]=4.17$ [1.06-16.40], $p<0.05)$ (Table 4).

\section{Sensitivity analysis}

Sensitivity analyses were performed using GEE models for the loss of NPI data at year-2 (data loss ratio $=26.4 \%$ ). In model 1 , any subject with a missing value for total NPI score at year- 2 was assigned the lowest score from baseline; in model 2, any subject with a missing value for total NPI score at year- 2 was assigned the highest score from baseline. In both models, GEE analyses did not show significant association $(p>0.05)$ between changes in total NPI score and baseline SVD markers, WMH progression, or multiple incident CMBs (data not shown).

\section{DISCUSSION}

This study examined the association of SVD progression with worsening of NPS, and their interaction on long-term clinical outcomes, in a dementia-free Asian elderly sample over 2 years. We determined that SVD burden was associated with a higher NPS score at baseline, and the progressions of SVD was associated with increase in the severity of NPS. 
Notably, we found that subjects having progressions of both SVD and NPS were more likely to develop incident cognitive decline. Our findings will have important implications on the clinical management of dementia-free elders with worsening of NPS.

Our cross-sectional results are in line with previous studies, which have consistently reported an association between SVD and apathy, depressive symptoms, and disinhibition in dementia-free elderly samples [13, 32-34]. Moreover, the present study has extended existing findings by exploring distinctive associations between neurobehavioral patterns and different SVD lesions. We identified the associations of WMH with more severe hyperactivity and apathy, and CMBs with more severe psychosis and affective symptoms at baseline. Our longitudinal results also demonstrated the persistence of such association, through a concurrent worsening of hyperactivity in the presence of WMH progression and worsening of psychosis in the presence of multiple incident CMBs.

Symptoms of hyperactivity are commonly found in patients with WMH $[35,36]$. It has been proposed that WMH disrupts neuronal network of the fronto-subcortical circuits through cerebral hypoperfusion, affecting normal function of decision-making and complex behavior, which lead to the occurrence of emotional and behavioral dysregulations $[35,37$, 38]. As neuropsychiatric disturbances are associated with disruptions of the dopaminergic and cholinergic neurotransmitter circuit, WMH in the fronto-straital and limbic regions may also be implicated in mood and behavioral disinhibition [32].

The manifestation of psychosis may be produced by CMBs, which are superparamagnetic hemosiderin deposits [23], through disrupted electrical activity leading to distributed neuronal dysfunction in the frontal, subcortical, and parietal regions [39-42]. It was suggested that CMBs located in the deep regions, such as basal ganglia, thalamus, brainstem, and cerebellum, are related to disrupted atherosclerotic microvessels linked to hypertension while lobar CMBs, such as those occurring in the temporal lobe and occipital lobe, are related to amyloid angiopathy underlying $\mathrm{AD}$ pathology [43]. Although previous studies have found a preliminary association between disinhibition with lobar CMBs but not with deep CMBs [13], data on the relationship between CMBs and NPS is scarce. Therefore, future studies could investigate the role of CMBs and their locations on neuropsychiatric patterns to better understand the potential mechanisms underlying CMBs and psychotic symptoms.

In addition to our team's previous finding that WMH progression is associated with cognitive and functional decline overtime [28], we further demonstrated that having progressions of both SVD and NPS presented an elevated risk of developing MCI or dementia. In this study, $6.5 \%$ of NCI subjects developed incident $\mathrm{MCI}$ and $5.9 \%$ of MCI patients progressed to dementia. This rate is consistent with other studies which reported comparable rates of conversion (5-10\%) over a period of 4 to 10 years [44-46]. As increasing attention has been paid to associate NPS as a risk factor of dementia [10], which may be mediated by SVD, early detection and management of these symptoms is therefore critical to improving disease outcome. The current findings may also guide clinicians in targeting SVD burden in clinical intervention, such as cardiovascular risk management, particularly in the earliest stage, as NPS are often not recognized until they become too disruptive to the patients and their caregivers.

Interestingly, the present study showed that only progressions of SVD are significantly associated with worsening of NPS in the long-term, whereas most baseline SVD markers did not predict changes in NPS over time. This may be due to the initially low SVD burden in a largely healthy dementia-free sample (51.2\% of subjects had a CDR score of 0 ), in which $34.1 \%$ had no SVD, $35.3 \%$ had only one SVD marker, $23.5 \%$ had two markers, and only $7.1 \%$ had all three markers. While previous studies have reported significant effects of SVD progressions particularly on increased depressive symptoms [38, 47, 48], we did not observe significant associations with affective subsyndrome in this study. This discrepancy could be due to the differences in scales for depression assessment and sample characteristics. On the other hand, the presence of depressive symptoms may have been masked by other symptoms that were not assessed by the NPI.

There are limitations to this study. First, the current findings do not reflect causation as the temporal relationship could not be determined. Second, as subjects were recruited from the memory clinic, our findings may not be generalizable to other samples. Third, the limited sample size has prevented us from examining the neurobehavioral correlates of region-specific SVD, such as lobar and deep CMBs, which are suggested to underlie different pathologies. Fourth, the current associations may be explained by nonvascular factors such as AD pathology. Although 
this study controlled for significant MTA as a surrogate marker of neurodegeneration, MTA may also be caused by other vascular processes or neurodegenerative diseases. Further studies could examine the influence of other AD biomarkers such as amyloid or tau burden. Fifth, we did not examine enlarge perivascular spaces (EPVS), which have emerged as another feature of SVD. However, EPVS may be nonpathogenic as they can occur in normal aging and are not associated with other MRI markers of SVD or cognitive function $[49,50]$.

Strengths of this study include the use of a longitudinal design to follow up on an elderly sample with a spectrum of cognitive status; availability of repeated and comprehensive investigations including MRI scans, neuropsychological assessments, and NPI to assess a broad range of behavioral and psychological symptoms of dementia; focus on older adults at a pre-dementia stage; and robustness of the analysis which took into account the confounding effects of vascular risk factors, neurodegeneration, and other large vessel disease markers.

\section{Conclusion}

In conclusion, the current associations between the progression of SVD, increasing severity of NPS, and worse cognitive performance provide valuable insight into the neurobiological correlates of NPS that could impact on current clinical management of NPS. As NPS are associated with specific SVD pathophysiology and maybe an early manifestation of dementia, early detection and management of SVD may improve NPS and possibly prevent or delay disease progression. SVD burden may be one of the factors to be targeted for clinical trial and management strategies to improve NPS outcome.

\section{ACKNOWLEDGMENTS}

We acknowledge all the Memory Aging \& Cognition Centre research personnel for their contribution to subject recruitment and data acquisition.

This study was supported by the National Medical Research Council grants: (NMRC/CG/NUHS/2010R-184-005-184-511, NMRC/CG/013/2013, NMRC/ CIRG/1446/2016).

Authors' disclosures available online (https:// www.j-alz.com/manuscript-disclosures/19-0999r1).

\section{REFERENCES}

[1] Pantoni LMD (2010) Cerebral small vessel disease: From pathogenesis and clinical characteristics to therapeutic challenges. Lancet Neurol 9, 689-701.

[2] Wardlaw JM, Smith C, Dichgans M (2013) Mechanisms of sporadic cerebral small vessel disease: Insights from neuroimaging. Lancet Neurol 12, 483.

[3] Catindig JA, Venketasubramanian N, Ikram MK, Chen C (2012) Epidemiology of dementia in Asia: Insights on prevalence, trends and novel risk factors. J Neurol Sci 321, 11.

[4] Venketasubramanian N, Sahadevan S, Kua EH, Chen CP, Ng TP (2010) Interethnic differences in dementia epidemiology: Global and Asia-Pacific perspectives. Dement Geriatr Cogn Disord 30, 492-498.

[5] Balestreri L, Grossberg A, Grossberg GT (2000) Behavioral and psychological symptoms of dementia as a risk factor for nursing home placement. Int Psychogeriatr 12, 59-62.

[6] Karttunen K, Karppi P, Hiltunen A, Vanhanen M, Välimäki T, Martikainen J, Valtonen H, Sivenius J, Soininen H, Hartikainen S, Suhonen J, Pirttilä T, ALSOVA study group (2011) Neuropsychiatric symptoms and Quality of Life in patients with very mild and mild Alzheimer's disease. Int $J$ Geriatr Psychiatry 26, 473-482.

[7] Okura T, Langa KM (2011) Caregiver burden and neuropsychiatric symptoms in older adults with cognitive impairment: The Aging, Demographics, and Memory Study (ADAMS). Alzheimer Dis Assoc Disord 25, 116-121.

[8] Xu X, Ang SL, Hilal S, Chan QL, Wong TY, Venketasubramanian N, Ikram MK, Chen CL (2015) Association of neuropsychiatric symptoms and sub-syndromes with cognitive impairment in community-dwelling Asian elderly. Int Psychogeriatr 27, 1839-1847.

[9] Beaudreau SA, Kaci Fairchild J, Spira AP, Lazzeroni LC, O'Hara R (2013) Neuropsychiatric symptoms, apolipoprotein $\mathrm{E}$ gene, and risk of progression to cognitive impairment, no dementia and dementia: The Aging, Demographics, and Memory Study (ADAMS). Int J Geriatr Psychiatry 28, 672680.

[10] Ismail Z, Smith EE, Geda Y, Sultzer D, Brodaty H, Smith G, Agüera-Ortiz L, Sweet R, Miller D, Lyketsos CG (2016) Neuropsychiatric Symptoms Professional Interest Area ISTAART Neuropsychiatric symptoms as early manifestations of emergent dementia: Provisional diagnostic criteria for mild behavioral impairment. Alzheimers Dement 12, 195-202.

[11] Ogawa Y, Hashimoto M, Yatabe Y, Kaneda K, Honda K, Yuuki S, Hirai T, Ikeda M (2013) Association of cerebral small vessel disease with delusions in patients with Alzheimer's disease: Small vessel disease and delusions in Alzheimer's disease. Int J Geriatr Psychiatry 28, 18-25.

[12] Wu RH, Li Q, Tan Y, Liu XY, Huang J (2014) Depression in silent lacunar infarction: A cross-sectional study of its association with location of silent lacunar infarction and vascular risk factors. Neurol Sci 35, 1553-1559.

[13] Xu X, Chan QL, Hilal S, Goh WK, Ikram MK, Wong TY, Cheng CY, Chen CL, Venketasubramanian N (2017) Cerebral microbleeds and neuropsychiatric symptoms in an elderly Asian cohort. J Neurol Neurosurg Psychiatry 88, 7-11.

[14] Narasimhalu K, Ang S, De Silva DA, Wong MC, Chang HM, Chia KS, Auchus AP, Chen CP (2011) The prognostic effects of poststroke cognitive impairment no dementia 
and domain-specific cognitive impairments in nondisabled ischemic stroke patients. Stroke 42, 883-888.

[15] Xu X, Hilal S, Collinson SL, Chong EJY, Ikram MK, Venketasubramanian N, Chen CL-H (2015) Association of magnetic resonance imaging markers of cerebrovascular disease burden and cognition. Stroke 46, 2808-2814.

[16] Albert MS, DeKosky ST, Dickson D, Dubois B, Feldman HH, Fox NC, Gamst A, Holtzman DM, Jagust WJ, Petersen RC, Snyder PJ, Carrillo MC, Thies B, Phelps CH (2011) The diagnosis of mild cognitive impairment due to Alzheimer's disease: Recommendations from the National Institute on Aging-Alzheimer's Association workgroups on diagnostic guidelines for Alzheimer's disease. Alzheimers Dement 7, 270-279.

[17] Cummings JL (1997) The Neuropsychiatric Inventory: Assessing psychopathology in dementia patients. Neurology 48, S10.

[18] Aalten P, Frans RJV, Boziki M, Brugnolo A, Bullock R, Byrne EJ, Camus V, Caputo M, Collins D, Peter Paul De D, Elina K, Frisoni G, Holmes C, Hurt C, Marriott A, Mecocci P, Nobili F, Ousset PJ, Reynish E, Salmon E, Tsolaki M, Vellas B, Robert PH (2007) Consistency of neuropsychiatric syndromes across dementias: Results from the European Alzheimer Disease Consortium: Part II. Dement Geriatr Cogn Disord 25, 1.

[19] Aalten P, Verhey FRJ, Boziki M, Bullock R, Byrne EJ, Camus V, Caputo M, Collins D, De Deyn PP, Elina K, Frisoni G, Girtler N, Holmes C, Hurt C, Marriott A, Mecocci P, Nobili F, Ousset PJ, Reynish E, Salmon E, Tsolaki M, Vellas B, Robert PH (2007) Neuropsychiatric syndromes in dementia. Results from the European Alzheimer Disease Consortium: Part I. Dement Geriatr Cogn Disord 24, 457.

[20] Wardlaw JM, Smith EE, Biessels GJ, Cordonnier C, Fazekas F, Frayne R, Lindley RI, O'Brien JT, Barkhof F, Benavente OR, Black SE, Brayne C, Breteler M, Chabriat H, Decarli C, de Leeuw FE, Doubal F, Duering M, Fox NC, Greenberg S, Hachinski V, Kilimann I, Mok V, Oostenbrugge R, Pantoni L, Speck O, Stephan BC, Teipel S, Viswanathan A, Werring D, Chen C, Smith C, van Buchem M, Norrving B, Gorelick PB, Dichgans M (2013) Standards for ReportIng Vascular changes on nEuroimaging (STRIVE, v1) Neuroimaging standards for research into small vessel disease and its contribution to ageing and neurodegeneration. Lancet Neurol 12, 822-838.

[21] Benjamin P, Trippier S, Lawrence AJ, Lambert C, Zeestraten E, Williams OA, Patel B, Morris RG, Barrick TR, MacKinnon AD, Markus HS (2018) Lacunar infarcts, but not perivascular spaces, are predictors of cognitive decline in cerebral small-vessel disease. Stroke 49, 586-593.

[22] Gregoire SM, Chaudhary UJ, Brown MM, Yousry TA, Kallis C, Jager HR, Werring DJ (2009) The Microbleed Anatomical Rating Scale (MARS): Reliability of a tool to map brain microbleeds. Neurology 73, 1759-1766.

[23] Martinez-Ramirez S, Greenberg SM, Viswanathan A (2014) Cerebral microbleeds: Overview and implications in cognitive impairment. Alzheimers Res Ther 6, 33.

[24] Werring DJ (2011) Cerebral microbleeds: Pathophysiology to clinical practice. Cambridge University Press, Cambridge, UK.

[25] Pantoni L, Basile AM, Pracucci G, Asplund K, Bogousslavsky J, Chabriat H, Erkinjuntti T, Fazekas F, Ferro JM, Hennerici M, O'Brien J, Scheltens P, Visser MC, Wahlund LO, Waldemar G, Wallin A, Inzitari D (2005) Impact of age-related cerebral white matter changes on the transi- tion to disability - the LADIS study: Rationale, design and methodology. Neuroepidemiology 24, 51-62.

[26] Hilal S, Mok V, Youn YC, Wong A, Ikram MK, Chen CL-H (2017) Prevalence, risk factors and consequences of cerebral small vessel diseases: Data from three Asian countries. $J$ Neurol Neurosurg Psychiatry 88, 669.

[27] Gouw AA, van der Flier WM, Fazekas F, van Straaten ECW, Pantoni L, Poggesi A, Inzitari D, Erkinjuntti T, Wahlund LO, Waldemar G, Schmidt R, Scheltens P, Barkhof F, LADIS Study Group (2008) Progression of white matter hyperintensities and incidence of new lacunes over a 3-year period: The Leukoaraiosis and Disability Study. Stroke 39, 1414-1420.

[28] Gyanwali B, Shaik MA, Tan BY, Venketasubramanian N, Chen C, Hilal S (2019) Risk factors for and clinical relevance of incident and progression of cerebral small vessel disease markers in an Asian Memory Clinic Population. $J$ Alzheimers Dis 67, 1209-1219.

[29] Hilal S, Saini M, Tan CS, Catindig JA, Dong YH, Holandez RL, Niessen WJ, Vrooman HA, Ting E, Wong TY, Chen C, Venketasubramanian N, Ikram MK (2015) Intracranial stenosis, cerebrovascular diseases, and cognitive impairment in chinese. Alzheimer Dis Assoc Disord 29, 12-17.

[30] Scheltens P, Launer LJ, Barkhof F, Weinstein HC, van Gool WA (1995) Visual assessment of medial temporal lobe atrophy on magnetic resonance imaging: Interobserver reliability. J Neurol 242, 557-560.

[31] Scheltens P, Polvd LA (2012) Atrophy of medial temporal lobes on MRI in "probable" Alzheimer's disease and normal ageing: Diagnostic value and neuropsychological correlates. J Neurol Neurosurg Psychiatry 83, 1038.

[32] Direk N, Perez HS, Akoudad S, Verhaaren BFJ, Niessen WJ, Hofman A, Vernooij MW, Ikram MA, Tiemeier H (2016) Markers of cerebral small vessel disease and severity of depression in the general population. Psychiatry Res Neuroimaging 253, 1-6.

[33] Kim HJ, Kang SJ, Kim C, Kim GH, Jeon S, Lee JM, Oh SJ, Kim JS, Choe YS, Lee KH, Noh Y, Cho H, Yoon CW, Chin J, Cummings JL, Lee JH, Na DL, Seo SW (2013) The effects of small vessel disease and amyloid burden on neuropsychiatric symptoms: A study among patients with subcortical vascular cognitive impairments. Neurobiol Aging 34, 19131920.

[34] Krishnan MS, O’Brien JT, Firbank MJ, Pantoni L, Carlucci G, Erkinjuntti T, Wallin A, Wahlund LO, Scheltens P, van Straaten ECW, Inzitari D, LADIS Group (2006) Relationship between periventricular and deep white matter lesions and depressive symptoms in older people. The LADIS Study. Int J Geriatr Psychiatry 21, 983-989.

[35] Berlow YA, Wells WM, Ellison JM, Sung YH, Renshaw PF, Harper DG (2010) Neuropsychiatric correlates of white matter hyperintensities in Alzheimer's disease. Int J Geriatr Psychiatry 25, 780-788.

[36] Hahn C, Lim H-K, Won WY, Ahn KJ, Jung W-S, Lee CU (2013) Apathy and white matter integrity in Alzheimer's disease: A whole brain analysis with tract-based spatial statistics. PloS One 8, e53493.

[37] Chen YK, Qu JF, Xiao WM, Li WY, Li W, Fang XW, Weng HY, Liu YL, Luo GP, Ungvari GS, Xiang YT (2015) Intracranial atherosclerosis and poststroke depression in Chinese patients with ischemic stroke. J Stroke Cerebrovasc Dis 25, 998-1004.

[38] van Sloten TT, Sigurdsson S, van Buchem MA, Phillips CL, Jonsson PV, Ding J, Schram MT, Harris TB, Gudnason V, Launer LJ (2015) Cerebral small vessel disease and association with higher incidence of depressive symptoms in 
a general elderly population: The AGES-Reykjavik Study. Am J Psychiatry 172, 570-578.

[39] Akoudad S, de Groot M, Koudstaal PJ, van der Lugt A, Niessen WJ, Hofman A, Ikram MA, Vernooij MW (2013) Cerebral microbleeds are related to loss of white matter structural integrity. Neurology 81, 1930-1937.

[40] Bonelli RM, Cummings JL (2007) Frontal-subcortical circuitry and behavior. Dialogues Clin Neurosci 9, 141.

[41] Heringa SM, Reijmer YD, Leemans A, Koek HL, Kappelle LJ, Biessels GJ (2014) Multiple microbleeds are related to cerebral network disruptions in patients with early Alzheimer's disease. J Alzheimers Dis 38, 211-221.

[42] Mega MS, Lee L, Dinov ID, Mishkin F, Toga AW, Cummings JL (2000) Cerebral correlates of psychotic symptoms in Alzheimer's disease. J Neurol Neurosurg Psychiatry 69, 167-171.

[43] Hommet C, Mondon K, Constans T, Beaufils E, Desmidt T, Camus V, Cottier JP (2011) Review of cerebral microangiopathy and Alzheimer's disease: Relation between white matter hyperintensities and microbleeds. Dement Geriatr Cogn Disord 32, 367

[44] Kirsch W, McAuley G, Holshouser B, Petersen F, Ayaz M, Vinters HV, Dickson C, Haacke EM, Britt W, 3rd, Larseng J, Kim I, Mueller C, Schrag M, Kido D (2009) Serial susceptibility weighted MRI measures brain iron and microbleeds in dementia. J Alzheimers Dis 17, 599-609.

[45] Mitchell AJ, Shiri-Feshki M (2009) Rate of progression of mild cognitive impairment to dementia meta-analysis of 41 robust inception cohort studies. Acta Psychiatr Scand 119, 252-265.
[46] Miwa K, Tanaka M, Okazaki S, Yagita Y, Sakaguchi M, Mochizuki H, Kitagawa K (2014) Multiple or mixed cerebral microbleeds and dementia in patients with vascular risk factors. Neurology 83, 646-653.

[47] Godin O, Dufouil C, Maillard P, Delcroix N, Mazoyer B, Crivello F, Alpérovitch A, Tzourio C (2008) White matter lesions as a predictor of depression in the elderly: The 3CDijon Study. Biol Psychiatry 63, 663-669.

[48] Teodorczuk A, O’Brien JT, Firbank MJ, Pantoni L, Poggesi A, Erkinjuntti T, Wallin A, Wahlund LO, Gouw A, Waldemar G, Schmidt R, Ferro JM, Chabriat H, Bazner H, Inzitari D, LADIS Group (2007) White matter changes and late-life depressive symptoms: Longitudinal study. Br J Psychiatry 191, 212.

[49] Gyanwali B, Vrooman H, Venketasubramanian N, Wong TY, Cheng C-Y, Chen C, Hilal S (2019) Cerebral small vessel disease and enlarged perivascular spaces-data from memory clinic and population-based settings. Front Neurol 10, 669 .

[50] Hilal S, Tan CS, Adams HHH, Habes M, Mok V, Venketasubramanian N, Hofer E, Ikram MK, Abrigo J, Vernooij MW, Chen C, Hosten N, Volzke H, Grabe HJ, Schmidt R, Ikram MA (2018) Enlarged perivascular spaces and cognition: A meta-analysis of 5 population-based studies. Neurology 91, e832-e842. 